\title{
Articles
}

Central European Review of Economics \& Finance

Vol. 19, No. 3 (2017), pp. 19-30. D0I: 10.24136/ceref.2017.010

Michał Gołębiowski ${ }^{1}$

\section{PERFORMANCE OF PUBLIC TASKS BY COMPANIES OF LOCAL GOVERNMENT UNITS}

The present article focuses on the issue of the provision of services of general economic interest by companies of local government units. Various parts discuss the basic requirements for entrusting the provision of this type of services to commercial companies, with particular reference to phenomena observed on a practical basis. It also addresses the aspects of diagnosed activities that bear signs of defectiveness, while stressing the importance of practices regarded as model. Collection and summary of conditions for the preparation and ordering the services from the sphere of public tasks was accompanied by the reflection on individual solutions, whose culmination are the observations relating to the recent changes in the national legislation and practice observed in other Member States.

JEL Classification Codes: H54, H76.

Keywords: local government units, public services.

\section{Introduction}

Local government units are responsible for the provision of a particular type of services in favor of the residents of an administratively-separated area. Ensuring their provision is of particular importance for meeting the basic needs of individuals, as well as effective implementation of the public authority. Following the criteria of a special method to regulate these services, they can be divided into several groups, namely: activities for the implementation of the public authority, social services and services of general economic interest.

For the purpose of this paper it was assumed that the implementation of the public authority includes all activities related to the implementation of

\footnotetext{
${ }^{1}$ M.A., Solicitor.
} 
the governmental authority, understood as an opportunity to develop the legal situation by persons outside the structure of public administration bodies, by means of decisions of the entity remaining the public administration body, within the meaning of the applicable law. Social services, referred to in the normative acts of the European Union, also as social services of general interest, relate to social security systems, covering the main risks of life and services of a preventive nature and contributing to the achievement of social cohesion and social exclusion (Implementation of the Community Lisbon Program, 2006) Services of general economic interest shall be understood as the sector of economic activity, which offers services of general public interest, which would not be provided or would be provided under different conditions, when it comes to quality, safety, affordability, equal treatment or public access, on the market without public intervention (Quality frameworks for services of general interest, 2011).

Due to the scope of this paper, it will discuss almost exclusively the issue of services of general economic interest by companies owned by local government units, together with selected aspects implemented in connection with this action in the field of the public authority. Time frames of individual observations will be set in particular by the date of the judgment of the Court of 24 July 2003 on C-280/00 (Altmark Trans GmbH, Regierungspräsidium Magdeburg against Nahverkehrsgesellschaft Altmark $\mathrm{GmbH}$ ) and the entry into force of the Act of 22 June 2016 on amendment of the Public Procurement Act and some other acts (Journal of Laws of 2016, item. 1020, 1579 and 1920) to the extent of the implementation of the relevant provisions of the European Union law (Directive of the European Parliament and of the Council 2014/24/EU; Directive of the European Parliament and of the Council 2014/25/EU). This paper aims at the recapitulation and discussion of requirements and practical aspects concerning the choice of the method of the provision of services of public interest by the company of the local government unit, with particular reference to the most common mistakes in this regard.

\section{Rules for the provision of services of public interest by companies of local government units}

Considerations on the possibility of ordering the task in the field of services of public interest to the company of the local government unit shall be started by a general conclusion about the unique nature of this type of solution, and thus the necessity of paying special attention to meeting a number 
of requirements in this regard. The first is the preparation of appropriate legal and organizational analyses, then the demonstration that the scope of services to be provided applies to services of public interest. The next step is the conclusion of an appropriate agreement that properly governs the scope of governmental authorities of the local government unit, as well as the mechanism for compiling and accounting the costs of the service. The completion of the service or the lapse of the period specified by law or agreement is followed by the audit of expenditures and settlements of the amount of compensation.

All the aforementioned requirements relate to the determination of the conditions for derogation from the principle of competitiveness when finding the entity responsible for the performance of the task, as well as meeting the conditions related to the services that can potentially be considered as state aid.

\section{Service of public interest ${ }^{2}$}

As indicated in the introduction, the services of general economic interest is a sector of economic activity, which offers services of general public interest, which would not be provided (or would be provided under different conditions, in terms of quality, safety, affordability, equal treatment or public access) on the market without public intervention.

Therefore, to provide the service of general economic interest, it must meet the basic needs of the citizens, which is covered by the category of public interest. The fact whether the services are of public interest, without full freedom in this regard, is decided by Member States, guided by the criterion of local conditions in the essential dimension. Thus, the solutions adopted in this regard shall be tailored to the needs of time and place. Therefore, considering the fact of entrusting the service for the provision to the company of the local government unit, it is necessary to determine whether, under the national legal order, there is an act specifying the provision as the service of public interest. If we refer to the sphere of services provided by local government units, basically their complete catalog is specified in Art. 7, paragraph 1 of the Act of 8 March 1990 on the local government (i.e. Journal of Laws of 2016 , item. $446,1579,1948)$. It is, however, still necessary to answer

\footnotetext{
2 For the purposes of this paper, the terms of „service of public interest” and „service of general economic interest" are treated as identical i.e. are characterized by the same group of designates, and thus will be used interchangeably.
} 
the question of whether the fact of remaining of the service one of the elements of a sample calculation, mentioned above, makes it possible to order its provision in the so-called in-house procurement and on the principles of derogation or exemption to the rules concerning state aid. In the opinion of the author of this paper, the answer must be negative, in spite of completely different practices in this regard.

First of all, we must refer to the definition of the service of general economic interest, quoted in the introduction. The provision of this type is an element of the catalog of services of basic importance, defined by the Member State, which shall be stressed, and which would not be provided or would be provided under different conditions, without public intervention. In the current economic environment there is a number of service providers, referred to in Art. 7, paragraph 1 of the Act on Local Government. Thus, before classifying the service as the service of general economic interest, it is necessary to examine whether in the case of choosing the competitive selection mode of the contractor, it would be possible to find the service provider and whether this would ensure the adequate level of its provision. The last of these criteria applies in particular to the parameters, such as: quality, safety, affordability, equal treatment and public access. It is important to generally verify the fact of compliance with the overriding principle in relation of services of public interest, namely providing continuity (persistence) of the provision of services and their availability. The research in this regard shall refer to the relevant market of enterprises capable of meeting the aforementioned requirements.

In the opinion of the author of this paper, in the course of analyses referred to above, which shall be written on paper, it is necessary to determine the level at which the service shall be provided. The current technical conditions allow for the achievement of high quality of the provision of municipal services, and thus the local community may have a legitimate expectation as to the quality of services provided. Therefore, this analysis shall cover not only the determination whether the competition existed in the relevant market, but whether it is possible to achieve relevant, precisely defined conditions for its provision. If the answer to that question is affirmative, in the opinion of the author of these considerations, there are no grounds to classify the service as the service likely to be the so-called in house procurement and taking into account the rigors resulting from the scope of the state aid rules. 


\section{Business aspects, organizational aspects and economic efficiency aspects}

In the course of preparation of entrusting the provision of the service of public interest to the company of the local unit government, it is necessary to precede such action by relevant analyses concerning not so much the service itself, but the considered manner of its provision. They are connected with the said uniqueness of the solution, in relation to the use of the competitive mode.

Entrusting the tasks to the company of the local government unit shall be preceded by business and organizational analyses, which will clearly indicate that individual projects are economically justified. This requirement relates to the purposes of operation of local government units, and is considered in this aspect, i.e. by identifying and defining the tasks of the local government in the data, personalized local conditions.

These analyses shall also justify the delegation of tasks to companies, as the best solution. In other words, from the point of view of the local government unit, the selected model shall be the most optimized from the organizational, legal and economic point of view. The burden of the demonstration of these features by the model lies with the commissioning entity, i.e. the local government unit. The control of practices of commissioning services points to the genesis of the defectiveness of this process in the absence of preparation of the described research (Supreme Chamber of Control, 2014).

The requirements applying to this kind of analyses refer to the necessity to prepare them in writing, in the period preceding the delegation of tasks to the company, and as to their reliability. The most difficult to meet is the requirement of the reliability of analyses. In this regard, it is necessary to avoid the preparation of documents according to the principles determining the fact of obtaining the desired application. Any observations made in these analyses shall be objectified, however, shall refer to the data and circumstances of the particular local government unit.

\section{Company as an internal operator}

The possibility to entrust the ability to provide services of public interest to the company of the local government unit, in the so-called in house procurement mode, is conditioned by the recognition of this type of company as an internal operator of the local government unit, within the meaning of the European Union law. According to the guidelines of the aforementioned judgment of the Court of 24 July 2003 on C-280/00, the internal operator will be 
the company managed by the unit acting as the owner. Thus, in the course of the analysis of the meeting of the discussed requirement, the research will cover the scope of the imperious influence of the local government unit in relation to the company.

In particular, in larger cities there comes to the separation of functions and tasks of the entity performing the powers in relation to the company, concerning the ownership supervisory, as well as the responsible local government unit for exercising the rights and obligations under the entrustment agreement. This kind of solution shall be considered as relevant in view of the differences resulting from legal aspects of the asset management, and the act as the parties to the civil law relationship. In the other Member States, the relationships are differently developed, but the Polish legal order may result in potential problems arising from the combination in a single entity of ownership management powers with those resulting from the commitment. The real risk is the fact of obliging the companies owned by local government units to perform non-rational acts from an economic point of view, but reasonable in relation to the demands of ownership. In the opinion of the author of this paper, this is a relatively significant problem, which needs to be discussed in a separate statement.

The subject of the research in this case will be the cumulative scope of powers applicable to the local government unit, regardless of the basis for their exercising. Therefore, this scope will include both the powers resulting from the entrustment agreement concluded, as well as those defined in the generally applicable provisions of law. In this regard, however, it is decisive to the local government unit to have all or most of the shares in the company.

\section{Object of economic activity of the company of the local government unit}

For the sake of the clarity of funding of services of general economic interest, including the possible verification of compliance with the state aid rules by competent bodies, it is legitimate for the company of the local government unit to not conduct other economic activity than the one covered by funding, as part of the construction of entrustment. On the basis of the specific legislation, in subsequent stages of the development, especially with regard to network sectors, there were formulated the requirements for the separation of the entity operation sphere in the field of services of public interest, and the remaining object of economic activity, in this case the company. Examples may include structural, accounting or organizational separation. Not entering into the area of detailed considerations in this regard, we shall 
opt for the concept of separation of the entity providing services of public interest, while to the remaining extent, which is increasingly practiced, transfer of other type of services to a separate company. Any other solution is conductive to the emergence or increase of the risk of the occurrence of the phenomenon of subsidizing the activity established outside the public utility sphere from public funds allocated for the performance of the service of general economic interest. Such a practice is forbidden in particular in terms of competition protection standards.

\section{Method of determination of the company's remuneration}

In the current development of regulations and views of the doctrine of law over the provision of services of general economic interest, there came to questioning the possibility of achievement of profits by companies of local government units, providing this type of service. However, in the context of classification of the phenomenon of provision of services of general economic interest to the economic activity sphere and its clear distinction from social services of a clearly non-economic nature, this position lost its base.

Given the above, the determination of the municipal company's remuneration shall be based on the following principles. The fundamental principle of financing of services of general economic interest is to incur the costs of the company's operation by public entities, but as mentioned earlier, only in terms of the provision of services of public interest. This means that the company must be entitled to receive the compensation for the costs actually incurred. In such cases, the remuneration is most commonly determined based on the cost calculation drawn up in advance, which is subject to the subsequent verification. When the expected costs of the service are higher than the assumed, the public entity is obliged to pay the specified cost, and respectively, in the case of lower costs of the service, the company shall make the appropriate reimbursement. Noting in this regard requires a faulty practice consisting in too general defining of calculation records. This document shall specify in detail the categories of costs to be incurred by the company, in relation to the designated manner of the provision of the service of general economic interest. The calculation will become the basis for the audit after the period of the provision of the service or after the lapse of the specified period for its provision.

As mentioned earlier, the basis for the decision on the selection of the service of public interest in the model of entrusting to the company of the local government unit, is the analysis indicating the economic efficiency of 
this solution. Hence, in the opinion of the author of this paper, confirmed by the position of control authorities, the cost of the provision of the service of public interest by the company shall be lower than in the case of commissioning the provision of the service under the competitive procedure. In other words, the provision of the service of public interest by the company, in terms of costs, shall be optimal with respect to the interest of the local government unit. As pointed out earlier, the determination of costs is the provision of the service at the appropriate level, tailored specifically to the legitimate expectations of members of the local community.

The element arousing the most controversy is the category of the company's profit. Only the transport-related regulations determine a precise rate of the company's profit. In other areas of activity, it is specified in the agreement concluded between the local government unit and the company. The correct practice in this regard focuses on shaping the amount of the profit in relation to the service provision cost. It shall be stressed that in accordance with the position expressed in practice, the company shall achieve the profit not higher than similar enterprises, i.e. enterprises providing similar services on the relevant market with the same features.

\section{Transferring the local government unit's assets to companies}

The issue of transfer of the local government unit's assets in terms of the current practice requires attention to two phenomena. The first is transferring the assets to companies without the support in a specific contractual relationship. It shall be clearly noted that if the company actually holds the assets as the owner, it must have the appropriate empowerment in this regard. Its basis is usually the contractual relationship, specifying the powers and responsibilities of each party. The absence of regulations in this regard results in the faulty practice. In particular, in the case of infrastructure sectors, it is necessary to ensure the maintenance of assets in a non-deteriorated condition, while maintaining the integrity and efficiency of its use, in order to ensure the operation of the local government unit.

Another kind of problem is the situation of transferring the ownership of certain assets to companies without the proper control over its use in an efficient manner and in accordance with the purpose of the transfer. In such situations, it is recommended to introduce the effective control mechanisms, based in particular on the rights of the ownership supervision that will enable the enforcement of the sound management of assets from the company and its use only for the provision of services of general economic interest. 
The postulated solution is to specify the best practice catalog in the field of management/ administration of entrusted public assets, or to appoint advisory teams of an interdisciplinary nature within the units exercising the substantive supervision.

\section{Summary}

The provision of services of public interest by companies of local government units remains the matter subjected to numerous regulations, mostly developed on the basis of practice and established based on the belief as to whether to increase the legal certainty in Altmark I and II packages ${ }^{3}$. In opposition to the belief that is practiced, the preparation and provision of services of general economic interest by companies in question, in accordance with the requirements outlined in this paper, is not a simple task devoid of risk. Substantive provisions in this regard stem from the basis on the principle of the uniqueness of these solutions and the model of competitive modes for awarding of contracts for such services.

The selection of the so-called in house procurement, in the system of entrusting and compensation of costs, is burdened with additional risks,

\footnotetext{
${ }^{3}$ The Altmark package I includes: Commission Decision of 28 November 2005 on the application of Art. 86, paragraph 2 of the EC Treaty for state aid in the form of compensation for the provision of public services, granted to enterprises obliged to manage the services of general interest (Official Journal of the EU of 29.11.2005, L 312/67); Community framework for state aid in the form of compensation for the provision of public services (Official Journal of the EU of 29.11.2005, C 297/4); Commission Directive 2005/81/EC of 28 November 2005 amending Directive 80/723/EEC on the transparency of financial relations between Member States and public enterprises and on the financial transparency within certain enterprises (Official Journal of the EU of 29.11.2005, L 312/47), replaced by: Commission Directive 2006/111/EC of 16 November 2006 on the transparency of financial relations between Member States and public enterprises, as well as on the financial transparency within certain enterprises (Official Journal of the EU of 17.11.2006, L 318/17).

The Altmark package II includes: Commission Decision of 20 December 2011 on the application of Art. 106, paragraph 2 of the Treaty on the Functioning of the European Union for state aid in the form of compensation for the provision of public services, granted to enterprises obliged to provide the services of general economic interest (Official Journal of the EU of 11.01.2012, L 7/3); Communication from the Commission on the European Union framework for state aid in the form of compensation for the provision of public services (Official Journal of the EU of 11.01.2012, C 8/15); Communication from the Commission on the application of the European Union rules in the field of state aid for the services of general economic interest (Official Journal of the EU of 11.01.2012, C 8/4).
} 
which are not discussed in this paper, such as, for example, overstaffing, inefficiency in the achievement of set goals, extending beyond the public utility sphere by companies, local jurisdiction or jurisdiction of tasks that can be performed by local government units. These phenomena, however, remain outside the discussion of this paper.

The prerequisite condition for the performance of public tasks in the described mode is to understand its nature and type of legal standards, in which it was established. The regulations in this regard were developed on the basis of the provisions falling within the scope of the acquis of the European Union, dominated by the teleological interpretation, rather than the linguistic interpretation as in the case of the Polish legal order. Worth noting are also the trends observed in other Member States, where there is a gradual withdrawal of the intervention of public entities and minimizing of the scope of services included in the area of public utilities. This corresponds to the conviction of the leading role of services offered on the competitive market, as well as the strict application of the state aid rules.

In the context of the Polish economic reality, there comes to the development of municipal companies and increase of the scope of services provided by them. It corresponds to the legislator's attempts to acquire, for example, the so-called in house procurements, specified in the provisions of the Public Procurement Act, while the directives referred to in the amendment of the Act of June 2016 situate the contracts entirely outside the public procurement sphere.

Taken the analyzed solutions as a whole, in the opinion of the author of this paper, they are the interesting solution and often the only solution to quickly provide services of public interest to the local community, in addition to services provided at the appropriate level. It is necessary, however, to meet all the requirements in this regard, so there are no situations limiting the economic development, as a result of the appropriation of the areas of gainful activity by public entities. 


\section{References}

Directive of the European Parliament and of the Council 2014/24/EU of 26 February 2014 on public procurement, repealing Directive 2004/18/EC, Official Journal of the EU L 94 of 28.03.2014, p. 65, as amended.

Directive of the European Parliament and of the Council 2014/25/EU of 26 February 2014 on procurements by entities operating in sectors of water management, energy, transport and postal services, repealing Directive 2004/17/EC, Official Journal of the EU L 94 of 28.03.2014, p. 243, as amended.

Gronkiewicz-Waltz H., Wierzbowski M. (2009). Economic law. Administrative and law issues, Warsaw.

Grzelakowski A. (2004). Policy in the field of transport, telecommunications and energy [in:] Brodecki Z. (ed.), Infrastructure, ed., Warsaw.

Implementation of the Community Lisbon Program: social services of public interest in the European Union (COM (2006) 177, final version of 26 April 2006.

Karasiewicz K. (2009). Services of general interest (in:) Piatek E., Karasiewicz K. (eds.) Quo Vadis Europa III?, UOKiK, Warszawa.

Karasiewicz K., Services of general economic interest: between the single market and the citizenship of the European Union (in:) Biernat S., Dudzik S. (eds.) Movement of people and provision of services in the European Union. New phenomena and trends.

Kawka I. (2008). The role of the European administration in the regulation of infrastructure sectors, Management Issues, No. 1.

Kociubinski J. (2011). The concept of services of general economic interest in the EU competition law, Europ. Judicial review, No. 8.

Kociubinski J. (2012). The application of the Altmark package (I and II) to aid granted to enterprises providing services of general economic interest, Wroclaw.

Kociubinski J. (2013). Services of general economic interest in the European Union Law. The challenge for the European economic model, Torun.

Krakala-Zielinska M. (2011). The importance of the universal service in the creation of the EU sector of services of general interest (in:) GronkiewiczWaltz H., Jaroszynski K. (eds.) The Europeanization of Public Economic Law, C.H.Beck, Warsaw.

Materna G. (2009). Organization of services of public interest in the light of competition law - commentary to the judgment of the Supreme Court of 20.11.2008 (III SK 12/08), Commentary, No. 3. 
Quality frameworks for services of general interest (2011). the Communication from the Commission to the European Parliament, the Council, the European Economic and Social Committee and the Committee of the Regions, Brussels.

Skoczny T. (2004). Protection of competition and pro-competitive sector regulation, Management Issues, No. 4.

Supreme Chamber of Control (2014). Performance of public tasks by companies established by local government units, Warsaw.

Szydlo M. (2005). Regulation of infrastructure sectors as a kind of state functions to the economy, Wydawnictwo Prawo i Praktyka Gospodarcza, Warszawa. 